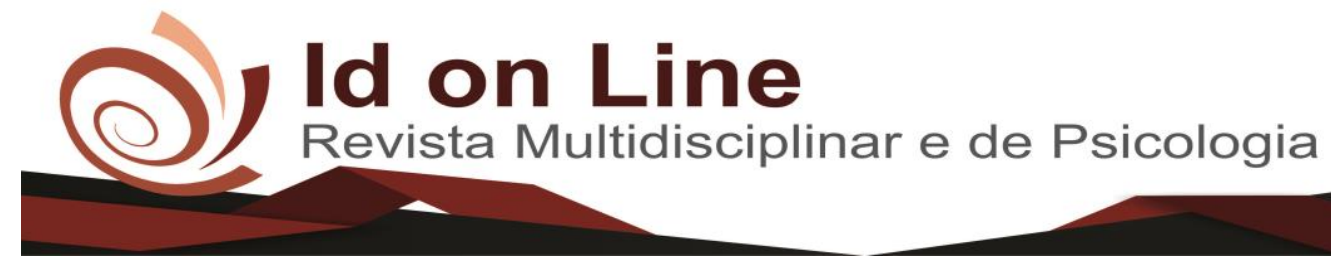

DOI: 10.14295/idonline.v13i48.2219

Artigo

\title{
Planejamento Tributário: Instrumento substancial no enquadramento Tributário em empresas industriais do setor calçadista no regime de tributação do lucro real e presumido
}

\author{
Aldir Dias de Amurim"; Antonia Valdelucia Costa²; \\ Cicero Silva de Oliveira Júnior ${ }^{3}$; Izabel Mônica Costa Silva Custódio ${ }^{4}$
}

\begin{abstract}
Resumo: No contexto organizacional a busca pela minimização da carga tributária deve refletir positivamente nos resultados das empresas. Este trabalho é realizado tendo como objetivo principal destacar a importância do planejamento tributário para as empresas. O desenvolvimento do estudo é abordado em pesquisas bibliográficas de caráter descritiva e com abordagem qualitativa. Ao longo do estudo, foram analisados e demonstrados vários pontos essenciais para a execução do planejamento tributário, ressaltando que as sociedades empresárias devem adotar essa ferramenta para garantir a redução legal dos tributos, onde é de suma importância que detenham responsabilidade e conhecimento sobre o assunto. E para concretizar foi realizado um planejamento tributário através de dados fictícios apresentados por meio de códigos fiscais de operações e prestações, para a escolha do melhor regime de tributação.
\end{abstract}

Palavras chave: Planejamento tributário. Lucro Real. Lucro Presumido.

\section{Tax Planning: Substantial instrument in the tax framework in footwear industrial companies under the tax regime of real and presumed profit}

\begin{abstract}
In the organizational context, the search for minimizing the tax burden should reflect positively on the companies' results. This work is carried out with the main objective of highlighting the importance of tax planning for companies. The development of the study is approached in bibliographical researches of descriptive character and with qualitative approach. Throughout the study, several essential points were analyzed and demonstrated for the execution of the tax planning, emphasizing that the companies must adopt this tool to guarantee the legal reduction of the taxes, where it is of paramount importance that they hold responsibility and knowledge on the subject. And in order to materialize, tax planning was carried out through fictitious data presented through tax codes of operations and benefits, to choose the best taxation regime.
\end{abstract}

Keywords: Tax Planning. Real Profit. Presumed Profit.

\footnotetext{
${ }^{I}$ Graduação em Ciências Contábeis pelo Centro Universitário Dr. Leão Sampaio - UNILEÂO. E-mail: aldirdias50@ gmail.com;

2 Graduação em Letras e em Direito pela Universidade Regional do Cariri. É especialista no ensino de Língua portuguesa pela Universidade Regional do Cariri; em Docência do Ensino Superior pela Faculdade Leão Sampaio; em Gestão Escolar e Psicopedagogia pela Faculdade João Calvino - BA, e em Educação Ambiental com Ênfase na Diversidade, pelo IFCE. Professora titular do Centro Universitário Dr. Leão Sampaio - UNILEÃO;

${ }^{3}$ Graduação em Ciências Contábeis pelo Centro Universitário Dr. Leão Sampaio, Brasil;

${ }^{4}$ Graduação em Ciências Contábeis pelo Centro Universitário Dr. Leão Sampaio, Brasil
} 


\section{Introdução}

No mundo empresarial a busca pela maximização dos lucros é uma prática bastante utilizada pelas empresas. Realizar o planejamento tributário é ter um melhor gerenciamento nas formas de economicidade e pagamento de seus tributos. Com a globalização da economia, tornou-se fundamental a correta administração do ônus tributário, buscando minimizar os custos sem comprometer o resultado da arrecadação.

O objetivo geral deste artigo é demonstrar a importância de se ter um planejamento tributário como ferramenta para garantir a redução legal dos tributos nas empresas, abordando os aspectos em atender as necessidades empresariais, analisando as modalidades de enquadramento tributário no lucro real e presumido e explorando a redução na carga tributária e a intensificação de seus resultados.

Para tanto, partiu-se da seguinte problemática: como uma empresa pode reduzir sua carga tributária de forma lícita, através do planejamento tributário? Esse problema foi levantado devido à alta carga tributária que as empresas devem pagar para o fisco no Brasil.

Diante do exposto o presente estudo justifica-se diante das mudanças que o cenário brasileiro vem passando, tornando visível o alto custo financeiro estipulado ao contribuinte e ainda, gerando a insegurança de estar ou não cumprindo com todas as obrigações exigidas. Assim, é evidente que o planejamento tributário seja um método de vasta relevância para garantir a redução legal dos tributos e competir em ambiente globalizado para auxiliar nas tomadas de decisões.

Na metodologia, utilizou a pesquisa bibliográfica de caráter descritiva e com abordagem qualitativa, enfatizando o quão é importante o planejamento tributário para as organizações, sendo possível também entender sobre elisão e evasão fiscal, os regimes tributários nas modalidades do lucro real e presumido e as apurações do IRPJ - Imposto de Renda de Pessoa Jurídica, CSLL - Contribuição Social sobre o Lucro Líquido, PIS - Programa de Integração Social e COFINS - Contribuição para o Financiamento da Seguridade Social, de acordo com dados fictícios apresentados por Códigos Fiscais de Operações e Prestações

Por fim, sendo apresentada a diferença dos valores dos impostos a recolher entre as formas de tributação do lucro real e presumido e o melhor regime de tributação a ser optado.

420 Id on Line Rev. Mult. Psic. V.13, N. 48 p. 419-434, Dezembro/2019 - ISSN 1981-1179 Edição eletrônica em http://idonline.emnuvens.com.br/id 


\section{Referencial Teórico}

\section{Tributo: Aspectos Históricos}

Conforme Correia (2018), os tributos surgiram a.C. e tinham como finalidade social ser usado como benefício do povo e não para atender as necessidades de um governante.

Segundo Rezende, Pereira e Alencar (2010), ao descobrir o Brasil em 1500, Portugal se preocupava em manter a posse das terras e examinar as suas riquezas para serem extraídas, adotando um tipo de cobrança que foi herdado e testado no mesmo. Com o passar do tempo e com a exploração das riquezas das novas terras, a Família Real precisou imigrar para o Brasil por causa do expansionismo napoleônico. Nos primeiros anos após a chegada da Família Real foram implantados novos tributos que começaram a ser cobrados nas novas terras. Devido à excessiva cobrança dos impostos por parte do Governo, houve reclamações por parte dos contribuintes para que a cobrança mudasse de alguma forma, mas pouco foi mudado. Nessa época, as riquezas começaram a ficar em escassez devido ao grande número de sonegações. Com isso, a legislação foi sendo modernizada pelos governantes e as fiscalizações e sanções foram ficando mais rígidas para quem não cumprisse com as normas.

Como se observa o tributo passou por várias fases de evolução limitada pelo poder de tributar e por ampliadores com garantias individuais e coletivas com devidos interesses. Atualmente os tributos são cobrados mediante uma enorme complexidade na carga tributária brasileira.

\section{Tributo}

De acordo com o artigo $3^{\circ}$ da lei 5.172 de 25 de Outubro de 1966, tributo é toda prestação pecuniária compulsória, examinado em moeda ou trabalho, cujo valor nela se possa exprimir, não alusivo à sanção de ato ilícito, que esteja instituída em lei e que seja cobrada através de uma atividade plenamente vinculada.

Dessa forma, compreende-se que o tributo é identificado pelo fato de sua origem, ou seja, fato gerador, que por meio deste, forma a obrigação imposta às pessoas físicas e jurídicas, de recolher pelo mesmo.

421 Id on Line Rev. Mult. Psic. V.13, N. 48 p. 419-434, Dezembro/2019 - ISSN 1981-1179 Edição eletrônica em http://idonline.emnuvens.com.br/id 
Para Harada (2018, p. 54),

O Estado, em virtude de seu poder de autoridade, pode retirar de seus súditos parcelas de suas riquezas para a consecução de seus fins, visando ao bem- estar geral. É o jus imperii do Estado que lhe faculta impor sobre as relações econômicas as praticadas pelos particulares, assim como sobre seus bens, o tributo que, na atualidade, se constitui em principal fonte de receita pública.

Portanto, o tributo é uma forma de assegurar recursos financeiros para o funcionamento do estado, designando-se como uma função fiscal. O tributo age como meio de intervir na sociedade e na economia, influenciando-se na estabilidade estadual, sendo assim uma função extrafiscal.

\section{Composição do Tributo}

A matéria tributária em consonância com o federalismo brasileiro, a União, os Estados e os Municípios, poderão instituir cinco espécies de tributos: impostos, taxas, contribuições de melhoria, contribuições especiais e empréstimos compulsórios.

A classificação destas espécies acontece por meio do valor arrecadado ou não, a uma contraprestação por parte do Estado, como também da natureza da atividade vinculada ou desígnio dos recursos (REZENDE; PEREIRA; ALENCAR, 2010).

É importante ressaltar um pouco sobre cada um dos tributos. Alexandre (2016) demonstra que imposto são competentes à União, aos Estados e aos Municípios. Além disso, é uma ramificação do tributo, e geralmente incide sobre manifestações de riqueza do sujeito passivo. As taxas são competentes a todos, são instituídas e cobradas perante a prestação de um serviço para comunidade ou quando é usado o poder de polícia. As contribuições são de possibilidades de todos, uma vez que a de melhoria necessita de uma específica autuação estatal, como um incremento do valor de imóveis pertencentes aos contribuintes. As especiais são as que têm intervenção no domínio econômico e quando é para uma destinação específica de interesse das categorias profissionais ou econômicas. Por exemplo: o PIS - Programa de Integração Social, o PASEP - Programa de Formação do Patrimônio do Servidor Público. Os empréstimos compulsórios por sua vez competem somente a União e pode ser criado em caso de calamidade pública ou para fim específico. 
Oliveira (2013) ressalta pontos sobre a definição e concretiza na essência que tributo é a obrigação imposta pelo sujeito ativo ao contribuinte independente da sua vontade, sendo essa obrigação extinta através do pagamento e evidencia que somente através de lei eficaz e válida que os tributos devem ser alterados ou instituídos.

Assim, pode-se afirmar que o Sistema Tributário Brasileiro é composto de princípios e normas que regulam os tributos instituídos no Brasil.

\section{Planejamentos Tributários}

As sociedades empresárias denominando o conhecimento obrigatório dos tributos na maioria de suas operações têm que procurar decisões estratégicas, imaginando o horizonte e evitando problemas posteriores, como também controlar a carga tributária sobre o seu patrimônio. Sendo assim, o planejamento tributário torna-se uma tática crucial e capaz de auxiliar nas tomadas de decisões.

Conforme Ribeiro e Pinto (2014) entende-se por planejamento tributário o cumprimento de atividade empresarial que tem como objetivo gerenciar e informar ao empresário as suas obrigações com as cargas tributárias e qual a melhor forma de reduzir o peso tributário, sem desobedecer os dispositivos legais.

Já para Crepaldi (2017), planejamento tributário é conhecer procedimentos como forma de economia de impostos para os contribuintes, determinando a melhor maneira de apurar os tributos e evitando riscos e desembolsos desnecessários.

O planejamento tributário pode ser realizado através de uma revisão fiscal, onde devem ser aplicados procedimentos como escolher a ação menos onerosa para a empresa, analisar a cobrança dos tributos e a possível cobrança indevida e a melhor forma de tributação do imposto de renda e contribuição sobre o lucro (CHAVES, 2017).

Para Fabretti (2009, p. 08),

O estudo feito proveniente, ou seja, antes da realização do fato administrativo, pesquisando-se seus efeitos jurídicos e econômicos e as alternativas legais menos onerosas, denomina-se Planejamento Tributário. O planejamento tributário exige, antes de tudo, bom senso do planejador. Há alternativas legais válidas para grandes empresas, mas que são inviáveis para as médias e pequenas, dado o custo que as operações necessárias para execução desse planejamento podem exigir. 
Dessa forma, entende-se que o planejamento tributário poderá nortear a atividade econômica da empresa, como também apresentar alternativas lícitas de determinada operação, antes da ocorrência do fato gerador, para que o contribuinte possa optar pela opção que represente o menor ônus tributário.

\title{
Elisão Fiscal
}

Atualmente várias empresas procuram um formato mais vantajoso para o pagamento da carga tributária; de certa forma existem diversas maneiras para eliminar ou postergar a tipificação desta obrigação e ficando a critério de cada empresa.

A Elisão fiscal nada mais é do que o comportamento do contribuinte em relação ao pagamento correto de seus tributos, seguindo as estratégias dentro da lei e procurando lacunas de alternativa lícita menos onerosa (FABRETTI, 2009).

Para Abrahão (2011), a elisão fiscal torna-se para o contribuinte uma arma crucial para a sua economia fiscal, tendo planejamento tributário diretamente relacionado com a elisão, tendo como propósito reduzir o pagamento do tributo por atos ou omissões lícitos do sujeito passivo antes mesmo da ocorrência do fato gerador.

Conforme Oliveira (2013, p. 193),

\begin{abstract}
A atuação do particular de se auto-organizar corresponde a um direito advindo da Constituição, pois é absoluta a garantia ao exercício da autonomia privada dentro dos limites estabelecidos pelo Estado. Dessa forma, a elisão fiscal pressupõe a licitude de comportamento do contribuinte que objetive identificar as consequências fiscais de uma decisão, resultando em uma economia de tributos, haja vista que, dentro do direito de se auto-organizar, está inserida a liberdade do contribuinte organizar seus negócios do modo menos oneroso sob o aspecto fiscal.
\end{abstract}

Enfim, a elisão acontece com um estudo minucioso, analisando pontos primordiais na legislação vigente, visando à efetivação do negócio com o menor ônus possível e tem que ser algo planejado para se chegar a uma decisão correta. 


\section{Evasão Fiscal}

A Evasão fiscal, ao contrário de elisão, utiliza-se de meios ilícitos correspondendo à sonegação ou fraude por parte do contribuinte, no intuito de ocultar ou diminuir o montante incidente sobre a carga tributária.

Segundo Fabretti (2009), evasão fiscal consiste na forma ilícita de economia fiscal, ou seja, é a prática contrária da legislação, realizada após a incidência do fato gerador do tributo. Por exemplo: a prestação de serviço por determinada clínica, e ao final não emitir a nota físcal para o cliente, essa ação é caracterizada omissão de receita, constituindo crime conta a ordem tributária.

Alexandre (2016) segue o mesmo raciocínio de Fabretti (2009), e complementa afirmando que a evasão fiscal é uma conduta em que o contribuinte pratica atos que visam a evitar o conhecimento da obrigação tributária pela autoridade fiscal, mesmo com a ocorrência do fato gerador.

A evasão fiscal é um problema que atinge diretamente a economia brasileira, por arrecadar inferior do previsto, e por torna-se um instrumento desleal, prejudicando o desenvolvimento da economia (ABRAHÃO, 2011).

Assim, pode-se afirmar que a evasão é um comportamento ilegal do contribuinte, tendo como finalidade a supressão da carga tributária, que em nenhum momento será resguardado pela legislação vigente.

\section{Regimes Tributários: Lucro Real e Presumido}

O planejamento tributário tem como missão propiciar informações íntegras e tempestivas para que a governança possa tomar decisões corretas. Cada regime tem suas particularidades e a administração juntamente com a governança tem que decidir qual opção de recolhimento dos tributos optar, para poder exercer as atividades durante o exercício.

Para Crepaldi (2017), o planejamento tributário é um dos fatores crucial dentro das estratégias de competitividades das empresas e que a sobrevivência do negócio requer conhecimento por parte do empresário sobre a carga tributária que incide sobre sua atividade, buscando soluções seguras e legais para sua diminuição. 
Assim, pode-se verificar que a escolha do regime tributário é de suma importância para o melhor desenvolvimento das organizações. Por isso, é necessário analisar de forma cautelosa todos os dados da empresa, pois a legislação não permite a mudança de regime no mesmo exercício. Sendo assim, será evidenciado a seguir, um pouco sobre as opções de tributação no lucro real e presumido, para melhor entender sobre o assunto.

\section{Lucro Real}

O lucro real é um regime de tributação mais complexo dentre os outros; essa forma de tributação está ao alcance de qualquer empresa e dependendo da atividade e do porte já estão obrigadas a fazerem parte dessa modalidade.

Para Ribeiro e Pinto (2014), lucro real é o lucro líquido do período, que é apurado mediante as adições, exclusões e compensações prescritas pela legislação do Imposto de Renda. Nesse contexto, Pêgas (2017) afirma que essa opção é mais vantajosa para as empresas que têm certo equilíbrio nos resultados, já que a base é o lucro contábil. É necessário abordar que a exigência por parte do fisco é bem alta, com isso, precisa de um controle qualificado, seja na análise da documentação, ou até mesmo um conhecimento aprofundado na legislação específica desta modalidade.

Para a apuração do IRPJ - Imposto de Renda de Pessoa Jurídica e CSLL - Contribuição Social sobre o Lucro Líquido, que são impostos calculados trimestralmente, têm como base de cálculo o lucro contábil apurado pela organização ajustada por adições relativas a despesas ou custos considerados indedutíveis, e por exclusões, relativas a receitas consideradas não tributadas e prejuízos fiscais de exercícios anteriores, aplicando-se a alíquota de $15 \%$ para o IRPJ, bem como há incidência do adicional de $10 \%$ sobre o valor do lucro real que ultrapassar $\mathrm{R} \$ 60.000,000$ ao trimestre e a alíquota de 9\% para a CSLL.

Por sua vez, as apurações dos impostos PIS - Programa de Integração Social e COFINS - Contribuição para o Financiamento da Seguridade Social, têm a incidência não cumulativa pelo regime tributário do lucro real, apurados mensalmente, tendo como base de cálculo o crédito pelas compras de mercadorias e o débito pelas vendas, tributando apenas a diferença, aplicando as alíquotas de $1,65 \%$ para o PIS e de 7,6\% para a COFINS. 


\section{Lucro Presumido}

O lucro presumido consiste na modalidade cumulativa, como também não apuram o lucro através de escrituração contábil, e sim pela presunção do lucro, pelos percentuais definidos na legislação.

Para Ribeiro e Pinto (2014), lucro presumido é uma forma de tributação mais simplificada e opcional. Neste caso, para determinação da base de cálculo do Imposto de Renda e Contribuição Social das pessoas jurídicas que não estiverem obrigadas a apurar pelo lucro real.

Já Pêgas (2017) enfatiza que é a modalidade onde a base de cálculo é obtida por meio de aplicação de percentual definido em lei, sobre a recita bruta da empresa. Além disso, comparando com o lucro real, a exigência é bem menor quanto ao controle da documentação exigida pelo fisco.

Para a apuração do IRPJ - Imposto de Renda de Pessoa Jurídica e CSLL - Contribuição Social sobre o Lucro Líquido que são impostos calculados trimestralmente, têm como base de cálculo a receita bruta da empresa deduzindo as devoluções de vendas e os impostos retidos nos documentos fiscais aplicando-se as alíquotas de presunção do lucro para as empresas de indústrias de calçados nos percentuais de $8 \%$ para o IRPJ e 12\% para a CSLL, em seguida aplicando-se as alíquotas básicas de 9\% para a CSLL e 15\% para o IRPJ.

Por sua vez, as apurações dos impostos PIS - Programa de Integração Social e COFINS - Contribuição para o Financiamento da Seguridade Social são feitas mensalmente, tendo como base de cálculo a receita bruta da empresa deduzindo as devoluções de vendas e os impostos retidos nos documentos fiscais, aplicando-se as alíquotas de 0,65\% para o PIS e 3\% para a COFINS.

\section{Metodologia}

O presente trabalho foi elaborado e fundamentado através de uma revisão bibliográfica tendo como referências livros e artigos relacionados ao assunto, de modo a possibilitar o seu aprofundamento. 
Para Marconi e Lakatos (2017), a pesquisa bibliográfica procura explicar um assunto através de referências teóricas publicadas, com a finalidade colocar o pesquisador frente ao que já foi escrito para reforçar suas pesquisas com as suas informações.

Quanto aos fins, o presente estudo caracteriza-se como uma pesquisa de caráter descritiva e com abordagem qualitativa.

A pesquisa descritiva é aquela onde o pesquisador preocupa-se em observar os fatos, analisá-los, registrá-los, classificá-los e interpretá-los, sem poder interferi-los. Assim, o pesquisador não pode manipular os fenômenos do mundo físico e humano, apenas estudá-los (ANDRADE, 2010).

O estudo elaborado de abordagem qualitativa, trata da análise dos dados para que se possa fornecer o melhor entendimento para o leitor, ressaltando e transmitindo conhecimento sobre a importância do planejamento tributário para as sociedades empresárias.

\section{Análises Demonstrativa}

Para o melhor entendimento do planejamento tributário, serão calculadas as apurações dos impostos apresentados anteriormente, IRPJ, CSLL, PIS e COFINS, de acordo com seu regime de tributação para que se possa escolher a melhor opção, através de dados fictícios por Códigos Fiscais de Operações e Prestações.

Tabela 1 - Códigos Fiscais de Operações e Prestações - CFOP

\begin{tabular}{clc} 
CFOP & \multicolumn{1}{c}{ Descrição } & Valor \\
1101 & Compra para industrialização ou produção rural & $143.463,33$ \\
1252 & Compra de energia elétrica por estabelecimento industrial & $197.740,52$ \\
1302 & $\begin{array}{l}\text { Aquisição de serviço de comunicação por estabelecimento } \\
\text { industrial }\end{array}$ & $10.133,20$ \\
1352 & Aquisição de serviço de transporte por estabelecimento & $58.053,73$ \\
1551 & Compustrial & $1.052,00$ \\
1556 & Compra de bem para o ativo imobilizado & $51.340,09$ \\
1908 & Entrada de bem por conta de contrato de comodato & 275,00 \\
2101 & Compra para industrialização ou produção rural & $370.616,11$ \\
2201 & Devolução de venda de produção do estabelecimento & $13.016,05$ \\
\hline
\end{tabular}

428 Id on Line Rev. Mult. Psic. V.13, N. 48 p. 419-434, Dezembro/2019 - ISSN 1981-1179 Edição eletrônica em http://idonline.emnuvens.com.br/id 
2352 Aquisição de serviço de transporte por estabelecimento

2551 Compra de bem para o ativo imobilizado

$6.367,51$

2556 Compra de material para uso ou consumo

2910 Entrada de bonificação, doação ou brinde

$13.636,24$

2911 Entrada de amostra grátis

69,30

717,27

2933 Aquisição de serviço tributado pelo ISSQN

264,00

Total:

868.289,78

5101 Venda de produção do estabelecimento

$23.668,51$

6101 Venda de produção do estabelecimento

$2.234 .719,84$

6107

Venda de produção do estabelecimento, destinada a não contribuinte

6109

Venda de produção do estabelecimento, destinada à ZFM ou ALC

$11.510,28$

6910 Remessa em bonificação, doação ou brinde

Total:

Fonte: Primária, 2019.

Tabela 2 - Apuração do IRPJ e da CSLL no Lucro Real

\section{Receita bruta operacional}

2.269.746,02

(-) Cancelamentos e devoluções de produtos

$(13.016,05)$

(-) Impostos incidentes sobre vendas de produtos

(=) Receita líquida operacional

1.936.206,92

(-) Custos diretos de produção

$(1.034 .773,57)$

(=) Lucro bruto operacional

$\mathbf{9 0 1 . 4 3 3 , 3 5}$

(-) Despesas operacionais

$(\mathbf{8 2 9 . 8 6 6 , 1 8 )}$

(-) Vendas

$(69.539,53)$

(-) Administrativas

$(500.120,55)$

(-) Financeiras

$(260.206,10)$

(+) Receitas financeiras

$\mathbf{9 8 4 , 5 0}$

(+) Outras receitas operacionais

786,57

(=) Resultado antes do IR e CS

73.338, 24

(-) IRPJ

$(11.000,74)$

(-) CSLL

$(6.600,44)$

(=) Lucro líquido do exercício

$\mathbf{5 5 . 7 3 7 , 0 7}$

Fonte: Primária, 2019. 
Tabela 3 - Apuração do PIS e da COFINS no Lucro Real

\begin{tabular}{|cccc}
\hline Descontos de créditos & Valor & PIS (1,65\%) & $\begin{array}{c}\text { COFINS } \\
(\mathbf{7 , 6 \%})\end{array}$ \\
Aquisição de insumos & $514.079,44$ & $8.482,31$ & $39.070,04$ \\
Energia elétrica & $197.740,52$ & $3.262,72$ & $15.028,28$ \\
Aquisição de serviço de transporte & $64.421,24$ & $1.062,95$ & $4.896,01$ \\
Total de créditos & & $\mathbf{1 2 . 8 0 7 , 9 8}$ & $\mathbf{5 8 . 9 9 4 , 3 3}$ \\
Débitos à alíquota básica & Valor & PIS (1,65\%) & COFINS \\
Venda de produção do estabelecimento & $2.260 .324,65$ & $37.295,36$ & $171.784,67$ \\
(-) ICMS ST & $(2.088,91)$ & $(34,47)$ & $(158,76)$ \\
(-) Devolução de Venda & $(13.016,05)$ & $(214,76)$ & $(989,22)$ \\
Bonificações e Amostra Grátis & 786,57 & 12,98 & 59,78 \\
Recebidas & Valor & PIS (0,65\%) & COFINS \\
Débitos à alíquota diferenciada & (4) $)$ \\
\hline Receitas Financeiras & & 6,40 & 39,38 \\
Total de débitos & & $\mathbf{3 7 . 0 6 5 , 5 0}$ & $\mathbf{1 7 0 . 7 3 5 , 8 6}$ \\
Valores a recolher & & $\mathbf{2 4 . 2 5 7 , 5 2}$ & $\mathbf{1 1 1 . 7 4 1 , 5 2}$
\end{tabular}

Fonte: Primária, 2019.

Tabela 4 - Apuração do IRPJ no Lucro Presumido

\section{Receita Bruta}

(-) ICMS ST

(-) Devolução de venda

(=) Receita antes da presunção

Lucro Presumido (8\%)

Receita de bonificação e amostra grátis

Receita Financeira

Base de Cálculo do IRPJ

IRPJ (15\%)

Adicional (10\%)

\subsubsection{4,93}

$(2.088,91)$

$(13.016,05)$

2.256.729,97

$180.538,40$

786,57

984,50

182.309,47

$27.346,42$

\section{IRPJ a Recolher}

27.346,42

Fonte: Primária, 2019.

430 Id on Line Rev. Mult. Psic. V.13, N. 48 p. 419-434, Dezembro/2019 - ISSN 1981-1179 Edição eletrônica em http://idonline.emnuvens.com.br/id 
Tabela 5 - Apuração da CSLL no Lucro Presumido

\section{Receita Bruta}

(-) ICMS ST

(-) Devolução de venda

(=) Receita antes da presunção

Lucro Presumido (12\%)

Receita de bonificação e amostra grátis

Receita Financeira

Base de Cálculo do CSLL

CSLL (9\%)
2.271.834,93

$(2.088,91)$

$(13.016,05)$

2.256.729,97

$270.807,60$

786,57

984,50

$272.578,67$

$24.532,08$

\section{CSLL a Recolher}

Fonte: Primária, 2019.

Tabela 6 - Apuração do PIS e da COFINS no Lucro Presumido

\section{Receita Bruta}

(-) ICMS ST

(-) Devolução de venda

(=) Receita antes da presunção
2.271.834,93

$(2.088,91)$

$(13.016,05)$

$2.256 .729,97$

\subsection{8,74}

67.701,90

COFINS a Recolher (3\%)

Fonte: Primária, 2019.

Tabela 7 - Resultado

LUCRO PRESUMIDO

PIS

COFINS

IRPJ

CSLL

TOTAIS
$14.668,74$

$67.701,90$

$27.346,42$

$24.532,08$
LUCRO REAL

$24.257,52$

$111.741,52$

$11.000,74$

$6.600,44$

Fonte: Primária, 2019. 
Feita a análise com base nos dados apresentados, é notório e perceptível à diferença que existe entre as duas formas de tributação, ficando o Lucro Presumido como melhor opção de tributação, por apresentar valores menores de recolhimento dos impostos apurados.

\section{Considerações Finais}

O presente trabalho teve como objetivo demonstrar a importância de se ter um planejamento tributário como ferramenta para garantir a redução dos tributos nas empresas, de forma lícita. As empresas vêm enfrentando muitos problemas devido à alta carga tributária, tornando-se um elemento que responde por grande parte dos gastos nas mesmas, fazendo com que se tornem obrigadas a tomar medidas para a melhor administração do ônus tributário.

Nesse contexto, torna-se indispensável a utilização do planejamento tributário, uma vez que é de suma importância efetuar estudos e análises sobre os sistemas de tributação, escolhendo o mais eficaz para suprir as necessidades da empresa e diminuir a carga tributária.

Utilizando-se de um planejamento tributário realizado através de dados fictícios apresentados por meio dos códigos fiscais de operações e prestações, tendo como segmento empresas industriais calçadistas no regime do lucro real e presumido e realizado as apurações do IRPJ, CSLL, PIS e COFINS nas duas modalidades e tributação. Pôde-se verificar que a opção pelo Lucro Presumido é realmente a mais vantajosa, por apresentar valores menores de recolhimento dos impostos apurados.

Dessa forma, ao realizar o planejamento tributário, foi possível destacar o quão é relevante à prática dessa ferramenta para as empresas, podendo ser um mecanismo para se obter sucesso dentro da legalidade.

\section{Referências}

ABRAHÃO, Marcelo Alcântara. A Elisão Fiscal como Ferramenta para o Planejamento Tributário. - Florianópolis: Universidade Federal de Santa Catarina, 2011. Disponível em: < http://tcc.bu.ufsc.br/Contabeis295994 >. Acesso em 30 Set. 2018. 
ALEXANDRE, Ricardo. Direito Tributário Esquematizado. 10 ed. - São Paulo: Método, 2016. Disponível em: < https://forumdeconcursos.com/wpcontent/uploads/wpforo/attachments/4032/189-Direito-Tributario-Esquematizado-10-Ed2016-Ricardo-Alexandre.pdf>. Acesso em 24 Set. 2018.

ANDRADE, Maria Margarida de. Introdução à Metodologia do Trabalho Científico. 10 ed. - São Paulo: Atlas, $2010 . \quad$ Disponível em: <https://integrada.minhabiblioteca.com.br/\#/books/9788522478392/cfi/4!/4/4@0.00:9.60>. Acesso em 18 Nov. 2018.

BRASIL. Lei 5.172 de 25 de Outubro de 1996. Dispõe sobre o sistema tributário nacional e institui normas gerais de direito tributário aplicáveis a união, estados e municípios. Código tributário nacional. Disponível em: <http://www.planalto.gov.br/ccivil_03/Leis/L5172.htm>. Acesso em 23 Set. 2018.

CHAVES, Francisco Coutinho. Planejamento Tributário na Prática: gestão tributária aplicada. 4 ed. - São Paulo: Atlas, 2017. Disponível em: < https://integrada.minhabiblioteca.com.br/\#/books/9788597011876/cfi/6/10!/4/18@0:0>.

Acesso em 26 Set. 2018.

CORREIA, Emanuelle Araujo. Evolução Histórica do Tributo: Limitações ao poder de tributar. Disponível em: <https://www.diritto.it/system/docs/28896/original/Artigo_Evolucao_Historica_do_Tributo_E manuelle_Correia.pdf>. Acesso em 22 Set. 2018.

CREPALDI, Silvio. Planejamento Tributário: teoria e prática. 2 ed. - São Paulo: Saraiva, $2017 . \quad$ Disponível em: < https://integrada.minhabiblioteca.com.br/\#/books/9788547217990/cfi/4!/4/4@0.00:0.00 >. Acesso em 23 Out. 2018.

FABRETTI, Láudio Camargo. Contabilidade Tributária. 11 ed. - São Paulo: Atlas, 2009.

HARADA, Kiyoshi. Direito Financeiro e Tributário. 27 ed. - São Paulo: Atlas, 2018. Disponível em: <https://integrada.minhabiblioteca.com.br/\#/books/9788597015744/cfi/6/24!/4/8/2/2@0:19.8 $>$. Acesso em 23 Set. 2018.

MARCONI, Marina de Andrade; LAKATOS, Eva Maria. Metodologia do Trabalho Científico. 8 ed. - São Paulo: Atlas, 2018. Disponível em: $<$ https://integrada.minhabiblioteca.com.br/\#/books/9788597012408/cfi/6/2!/4/2/2@0.00:0.00 $>$. Acesso em 18 Nov. 2018.

OLIVEIRA, Gustavo Pedro de. Contabilidade Tributária. 4 ed. - São Paulo: Saraiva, 2013. Disponível em: https://integrada.minhabiblioteca.com.br/\#/books/9788502204621/cfi/4!/4/4@0.00:10.6>. Acesso em 25 Set. 2018. 
PÊGAS, Paulo Henrique. Manual de Contabilidade Tributária. 9 ed. - São Paulo: Atlas, $2017 . \quad$ Disponível em: <https://integrada.minhabiblioteca.com.br/\#/books/9788597011890/cfi/6/10!/4/18@0:12.5>. Acesso em 24 Out. 2018.

REZENDE, Amaury José; PEREIRA, Carlos Alberto; ALENCAR, Roberta Carvalho de. Contabilidade Tributária: entendendo a lógica dos tributos e seus reflexos sobre os resultados das empresas. 1 ed. - São Paulo: Atlas, 2010. Disponível em: <https://integrada.minhabiblioteca.com.br/\#/books/9788522480173/cfi/4!/4/4@0.00:10.4>. Acesso em 23 Set. 2018.

RIBEIRO, Osni Moura; PINTO, Mauro Aparecido. Introdução à Contabilidade Tributária. 2 ed. - São Paulo: Saraiva, 2014. Disponível em <https://integrada.minhabiblioteca.com.br/\#/books/9788502220607/cfi/7!/4/4@0.00:58.3>. Acesso em 26 Set. 2018.

\section{Como citar este artigo (Formato ABNT):}

AMURIM, Aldir Dias de; COSTA, Antonia Valdelucia; OLIVEIRA JÚNIOR, Cicero Silva; CUSTÓDIO, Izabel Mônica Costa Silva. Planejamento Tributário: Instrumento substancial no enquadramento Tributário em empresas industriais do setor calçadista no regime de tributação do lucro real e presumido. Id on Line Rev.Mult. Psic., Dezembro/2019, vol.13, n.48, p. 419-434. ISSN: 19811179.

Recebido: $23 / 11 / 2019$

Aceito: 29/11/2019 